Horne, D. J. 2018. Young, small-scale surface features in Meridiani Planum, Mars: A possible signature of recent transient liquid and gas emissions. Planetary and Space Science, 157, 10-21.

Accepted 11 April 2018

\title{
Young, small-scale surface features in Meridiani Planum, Mars: A possible signature of recent transient liquid and gas emissions
}

\author{
David J. Horne
}

School of Geography, Queen Mary University of London, Mile End Road, London E1 4NS, UK. Tel. +44 (0)207 882 7619. Email: d.j.horne@qmul.ac.uk

\begin{abstract}
Enigmatic small-scale $(<1 \mathrm{~m})$ depositional and erosional features found in basaltic sands partly covering bedrock exposures, imaged at several locations in the equatorial Meridiani Planum region by the Mars Exploration Rover Opportunity, may be evidence of previously unrecognized, geologically young (or even contemporary) Martian surface processes. Leveed fissures appear to have formed by venting from beneath; possible explanations include aeolian blowholes near crater margins, volcanic fumarole activity, or gas/vapour escape resulting from the decomposition of small pockets of ground ice, methane clathrates or hydrated sulphate minerals. Some leveed fissures cross-cut and are therefore younger than aeolian ripples thought to have last been active c. 50,000 years ago. Erosional gutters are sharply defined and fresh-looking, internally terraced, sometimes are deeper near one end, and in one case seem to give way to small depositional fans downslope; they have the appearance of having been formed by liquid flow rather than by wind erosion. There is evidence elsewhere that contemporary ground-ice thaw and consequent transient surface run-off may occur occasionally under present conditions at low, near-equatorial latitudes on Mars; short-lived (even for just a few minutes) meltwater emission and flow at the surface could form gutters before evaporating. Further possibilities are the decomposition of buried pockets of methane clathrates (which theoretical considerations suggest might be present and stable even in equatorial regions) giving rise to both methane gas venting and transient surface water, or the release of liquid brines by decomposition of hydrated magnesium sulphate minerals or deliquescence of perchlorates. Dry granular flow mechanisms proposed as explanations for Recurring Slope Lineae seem inadequate to explain the morphologies of leveed fissures and gutters.
\end{abstract}

Keywords: Mars; surface processes; aeolian; transient liquids; transient gases

\section{Introduction}

Indications of Martian surface processes active within the past few hundred thousand years, including aeolian ripples and impact cratering, have been documented by the Mars Exploration Rover (MER) Opportunity in the Meridiani Planum region (Fig. 1) close to the Martian equator (Golombek et al., 2010). Evidence of additional and hitherto-unrecognized surface processes is offered by two types of geologically young, small-scale features imaged by Opportunity between 2004 and 2017: (1) leveed fissures and (2) gutters. Both occur in loose, dark soils which partly cover the light-toned bedrock exposed at the surface. Soils traversed by Opportunity are typically poorly-sorted, fine-grained $(\sim 0.05-0.2 \mathrm{~mm})$ basaltic sands, with coarser $(1-5 \mathrm{~mm})$ sands on aeolian ripple surfaces rich in hematite spherules ("blueberries") eroded from the underlying sulfate-rich sedimentary rock layers of the Burns Formation (Golombek et al., 2010; Kocurek and Ewing, 2012). 


\section{Methods}

Features of interest were first identified by visual inspection, on the NASA/JPL-Caltech Mars Exploration Rovers website (http://mars.nasa.gov/mer/home/), of HazardCamera (HazCam), Navigation camera (NavCam) and Panoramic Camera (PanCam) images obtained by the MER Opportunity between sols 1 and 4720. Selected raw images were downloaded for further study, including stereo pairs and, where possible, multiple views of the same feature from different angles and locations, and with different illumination angles, all of which affect how the relief of geomorphological features appears. Locations were mapped with reference to annotated route maps available on the NASA/JPL-Caltech Mars Exploration Rovers website. The sizes of features seen in oblique images were estimated with reference to uncropped equivalent images showing MER wheel tracks, which are approximately $1 \mathrm{~m}$ apart (Fig. 2), or proximity to MER components such as wheels or the instrument package on the robotic arm. Scale bars added to images are therefore necessarily approximate. Images used in figures herein have been adjusted for contrast and brightness and in some cases cropped. Locations of the observed features were mapped on the route explored by Opportunity (Fig. 3) and tabulated with details of selected images (Table 1).

\section{Small-scale surface features}

\subsection{Leveed fissures}

Leveed fissures (Figs 4-9, 11A) are narrow, elongate, steep-sided depressions flanked by raised levees or half-cones of soil. The fissures are typically c. 5-20 cm wide and up to c. $50 \mathrm{~cm}$ long (e.g. Fig. 4), although at some sites they form more extensive connected patterns (e.g. Fig. 8). They taper acutely at their ends; some are straight, some curved or irregular, and a few bifurcate (e.g., Fig. 4B). They appear to correspond to fractures in the underlying bedrock. The levees are thickest (c. $1-5 \mathrm{~cm}$ high) proximal to the fissures and thin towards their diffuse outer boundaries c. 10-15 cm from the fissures. Some appear fresh and sharp (Figs 4, 5), others softened, perhaps by wind erosion (Fig. 11A); some at the edges of rock slabs have levees on one side only (Fig. 7). Leveed fissures have been observed in at least 36 locations (Table 1).

\subsection{Gutters}

Gutters (Figs 10,11) are elongate, straight or sinuous surface depressions, typically 2-10 $\mathrm{cm}$ wide and $1-5 \mathrm{~cm}$ deep, sometimes deeper at or near one end. Fresh-looking ones are sharp-edged, but these are relatively rare and have been observed in only five locations (Table 1); more common but less clearly-marked linear depressions may possibly be gutters that once looked the same but have been softened and subdued by wind erosion and partial infilling with dust (e.g., Fig. 11A). At a location named Gibraltar (Sol 2668 - Sol 2670), outside the western rim of Endeavour crater near Cape York, a pair of sharply-defined gutters in dark soil, on either side of a light-toned flat slab of rock, appear to emanate (or terminate) beneath another somewhat higher-standing rock (Fig. 11B-D); contextual images show that the general area is relatively flat with minor undulations, and localised slopes in the immediate vicinity of these features are very gentle (estimated $<5^{\circ}$ ). The right-hand gutter has a relatively flat floor and its sides are undercut in places so that small flakes of the thin surface crust of the soil have collapsed, intact, into it. The left-hand gutter is internally terraced upslope (further from the camera) and then seems to pass under the rock downslope (towards the camera). Both have very irregular margins. Proximal to the camera, both gutters appear to give way to fans of dark soil spread across the surface of the light-toned rock; the full extent of these fans is not observable in any available images, and if there was only one it might be explained as a ripple tip that happens to coincide with the end of a gutter, but the presence of two such features close together, with similar morphology and orientation, is suggestive of a relationship between fan and gutter that is more than coincidental. A gutter on the rim of Endurance crater, which previously occasioned speculation about the possibility of transient liquid water on the surface 
(Horne, 2005), is associated with elongate hollows near its upslope end and runs downslope towards the crater (Fig. 10A, B). In contrast with the rest of the gutter, which has a smooth, lighttoned floor, the upslope hollows, only a few $\mathrm{mm}$ deeper, are floored with an irregular surface of dark-toned material. A more prominent, terraced gutter close to the rim of Endurance crater (Fig. $10 \mathrm{C}-\mathrm{E})$, running alongside the edges of rock slabs, is deepest at its downslope end; associated with it on the side distal to the rock slabs is a distinct collar-like zone, up to c. $0.25 \mathrm{~m}$ wide, where the dark "blueberry"-rich soil appears to be coated with light-toned fine dust.

\section{Age considerations}

The leveed fissures cross-cut and are therefore younger than the aeolian ripples that are a characteristic surface feature of the region (e.g. Figs 4, 5). Using observations of fresh impact craters and ejecta superimposed on the ripples, Golombek et al. (2010) were able to estimate that the most recent phase of migration of the ripples was between about 50 and $200 \mathrm{ka}$. It follows that the maximum age of the leveed fissures, which cross-cut the ripples, could be as young as $\sim 50 \mathrm{ka}$; the sharper, fresher-looking examples of these features could be much more recent in origin. In the absence of observed cross-cutting relationships it is not possible to establish a minimum age for gutters, but the fresh appearance of a few and the apparent association of some with leveed fissures suggest that they, too, are relatively young.

\section{Interpretation and discussion}

\subsection{Interpretation}

Although there is an apparent alignment of some examples with underlying bedrock fractures there is no evidence that the morphology of leveed fissures is due to simple draping of soil over hidden bedrock structures, so they are interpreted as primary depositional and/or erosional features formed in loose sediment. The possibility that they formed by sediment sinking into underlying voids through cracks in the bedrock is rejected because a very large void volume would have to exist if it was still not filled up after tens of thousands of years' worth of aeolian sand ripples migrating over them, although it must be admitted that seismic shaking caused by meteorite impact might widen joints in the bedrock, at the same time mobilising the sand so that it would sink into the newly available voids. While these phenomena might explain the fissures, however, they cannot explain the positive relief of their raised levees (e.g., Fig. 4B).

It is difficult to think of any explanation for leveed fissures that does not involve the venting of material from beneath. Such vents could be formed by volcanic gases (fumarole activity), but there is no other evidence of geologically young volcanic activity in the region. Another possibility is that they are blow-holes formed by wind entering interconnected voids in the bedrock in one place and escaping in another; this seems unlikely in the plains setting of many examples, although more plausible if close to the rim of a deep crater. Moreover, winds strong enough to form the features in this way would presumably render the aeolian ripples active at the same time, so it is difficult to understand how the leveed fissures could disrupt the ripple morphologies so distinctly.

Other possibilities, considered below in more detail, are that they are formed by the recurrent formation and sublimation of $\mathrm{CO}_{2}$ frost (5.2), by melting ground ice leading to the boiling of metastable water or brine (5.3), by venting gas such as methane released by decomposing small pockets of methane-water clathrates postulated to be present in subsurface regolith or bedrock (5.4) or by processes involving liquid brines (5.5).

It is possible that gutters could be excavated by wind action but their often sharp-edged and sometimes internally terraced morphology is more suggestive of erosion by flowing liquid water or brine, perhaps originating from melting ground ice and running on the surface for a few minutes before evaporating. Gutters might be considered as similar and perhaps related to Recurring Slope Lineae (RSL) and gullies observed on the inner slopes of craters, including examples in close to the equator (albeit in the depths of Valles Marineris), although they are 
much smaller (typically a few $\mathrm{cm}$ wide and $<1 \mathrm{~m}$ long) than RSL (a few m wide and $100 \mathrm{~s}$ of $\mathrm{m}$ long) (McEwen et al., 2011, 2014; Schmidt et al., 2017). Explanations for RSL and gully formation include contemporary water or liquid brine flow (e.g., Head et al., 2008; McEwen et al., 2011; Ohja et al., 2015) and dry granular flow (Shinbrot et al., 2011; Schmidt et al., 2017). Dry granular flow cannot be ruled out for the Meridiani gutters but it seems unlikely that it would have adequate erosive power on surfaces that are near horizontal or very gently sloping; RSL seem to be restricted to slopes steeper than c. $25^{\circ}$ (McEwen et al., 2011) while Meridiani gutters have been observed on slopes of less than c. $15^{\circ}$. Three well-defined, sub-parallel, $10-20 \mathrm{~cm}-$ wide dark streaks were imaged by Opportunity on the steep face of Burns Cliff (slope c. $45^{\circ}$ ) inside Endurance crater, one of which lengthened downwards by approximately $20 \mathrm{~cm}$ between sols 263 and 268 (Fig. 12) but it cannot be determined whether they formed by wet or dry processes and they were below a different section of the rim than where gutters were imaged on the rim and outer slope of Endurance between sols 114 and 123.

It cannot be entirely ruled out that Opportunity herself might trigger changes by moving over the ground surface or by affecting the local thermal environment enough to cause shortlived ground-ice melting and transient liquid flow. In at least one case, however, near the rim of Endurance crater, it can be ascertained from images taken on successive sols (114-123) that a gutter already existed before the closest approach by Opportunity. In this particular example, the gutter appears to deepen downslope to its termination in a deeper hollow (Fig. 10C-E), which implies surface liquid draining into a void below the surface. It would normally be expected that if a gutter was formed by liquid emerging from the ground, the point of emergence would be at the upslope end of the feature; in this case, situated on the outer slope of the uplifted rim of the crater, any liquid emerging from the hole must have flowed uphill (which is not impossible if it emerged as a jet under pressure) and then flowed back to drain into the subsurface again. The "collar" of fine sediment coating the surface adjacent to the downslope end of the gutter may be evidence that material was sprayed out along a fissure, in which case this particular feature might be regarded as hybrid leveed fissure and gutter. The gutters at Gibraltar (Fig. 11B-D) could alternatively be explained as dry fractures resulting from a disturbance of the slab of rock when Opportunity ran a wheel over it, although this would not account for the small depositional fans at the proximal ends of the gutters, which have sharp and irregular boundaries suggestive of emplacement by liquid rather than wind.

\section{$5.2 \mathrm{CO}_{2}$ frost}

Using the Mars Climate Sounder on the Mars Reconnaissance Orbiter, Piqueux et al. (2016) demonstrated widespread occurrence of surface temperatures consistent with the condensation of $\mathrm{CO}_{2}$ frost on the surface during the night at middle and low latitudes, followed by its sublimation in the morning. They suggested that such a recurrent process could enable dynamic phenomena such as the fluidisation and avalanching of dusty surface deposits on shallow slopes at low latitudes. This could suggest at least a contributory mechanism for the formation of leveed fissures and gutters, but on its own it seems inadequate to explain such discrete, localised features with significant positive and negative relief. Although such conditions have not been observed in Meridiani Planum the possibility that they occurred there occasionally during the past few thousand years cannot be excluded.

\subsection{Ground ice}

Ground ice could potentially supply mechanisms involving sublimation and/or melting for the formation of small-scale surface features. Some patterns of leveed fissures imaged by Opportunity (e.g. Fig. 8) bear some resemblance to the thermal contraction cracks (often with raised shoulders similar to fissure levees) found in the hyper-arid Antarctic Dry Valleys on Earth (Levy et al., 2008, 2009) where they form polygonally patterned ground. Since the Antarctic examples typically develop where there is extensive pore ice in soil within about $1 \mathrm{~m}$ of the surface, the Martian examples might imply the geologically recent (or even contemporary) presence of shallow ground ice. However, networks of complete polygons have yet to be observed by Opportunity, and the few complete or partial polygons seen are smaller $(<1 \mathrm{~m}$ 
diameter) than the Antarctic ones (typically $>10 \mathrm{~m}$ diameter). Moreover, Gamma Ray Spectrometer observations by the Mars Odyssey orbiter and modelling studies have concluded that ground ice must very deep or unstable in low and equatorial latitudes, and a shallow $(<1 \mathrm{~m})$ ice table can only be present and stable at latitudes higher than $49^{\circ}$ beneath level ground (Schorghofer and Aharonson, 2005) but can extend to latitudes as low as $25^{\circ}$ on pole-facing slopes (Aharonson and Schorghofer, 2006; Vincendon et al., 2010). The similarity may be coincidental and the polygons in Meridiani Planum could be related to polygonal joint patterns in the underlying bedrock. Head et al. (2008) proposed localised melting of residual ice from geologically-recent glaciation to explain the origin of young gullies in crater walls at mid-latitudes of Mars (poleward of $30^{\circ}$ ), and there is evidence for significant amounts of extant buried ice at low, even equatorial latitudes (Balme et al., 2013; Burr et al., 2005; Gouronc et al., 2014; Head et al., 2005; Murray et al., 2005; Shean, 2010), as well as theoretical / modelling support for the notion of transient liquid water on the surface (e.g. Hecht, 2002; Hecht and Vasavada, 2006; Levin and Weatherwax, 2004). Mangold (2011) considered it unlikely that any equatorial ice occurs close to the surface today, but commented that its presence at depths exceeding $10 \mathrm{~m}$ cannot be excluded. The area of Meridiani explored by Opportunity lies approximately $2^{\circ} S$ of the equator (Fig. 1). At the present obliquity of about $25^{\circ}$, unprotected ground ice is considered to be unstable at latitudes less than $40-50^{\circ}$, but at obliquities of about $32^{\circ}$ and higher (which last occurred c. 0.5 million years ago) ground ice may be stable everywhere with the top of the ice $5-10 \mathrm{~cm}$ below the surface (Carr, 2006). This is supported by some of Steele et al.'s (2017a) simulations which show, at an obliquity of $45^{\circ}$, stable subsurface ice forming in low and midlatitudes at depths less than $1 \mathrm{~m}$, due to more abundant atmospheric water vapour.

Jakosky et al. (2005) suggested that, unlike the present situation with a south-polar icecap covered in $\mathrm{CO}_{2}$ ice all the year round, a more representative state for recent epochs might be one in which the south-polar ice-cap loses some of its $\mathrm{CO}_{2}$ ice cover during the summer, exposing the water ice-cap and enhancing the atmospheric water content to the extent that water ice could be stable over most of the planet. They argued that in such a situation water could diffuse into the subsurface, allowing a significant amount of ice to condense in the regolith in a few thousand years. Jakosky et al. (2005) suggested that this state could have existed as recently as a few decades ago and low-latitude water-ice may have survived to the present day if isolated from the atmosphere, for example by a cemented layer in the soil or simply by very fine-grained regolith which, it has been argued, could inhibit sublimation and preserve ice, even for billions of years and even at the equator (Smoluchowksi, 1968; Mangold, 2011). In the deep trough of Valles Marineris which lies between the equator and about $10^{\circ} \mathrm{S}$ latitude, the persistence of enormous volumes of ancient relict ice, protected from sublimation by a cover of ablation till, has been postulated by Gouronc et al. (2014). Further East, in Cerberus Fossae around latitude $5^{\circ} \mathrm{N}$ in the western Elysium Basin region, fractured plates up to $30 \mathrm{~km}$ across, showing evidence of lateral drift, break-up and rotation, have been interpreted as pack-ice on a frozen lake now covered and insulated by a protective layer of volcanic tephra (Murray et al., 2005; Balme et al., 2010), although others have argued that the plates and the polygonally textured areas between them represent different lava flow surfaces (Dundas et al., 2010) and Mars Odyssey Neutron Spectrometer (MONS) data show no evidence of hydration in this area (Wilson et al., 2018). The Athabasca Valles region (approx. $10^{\circ} \mathrm{N}$; also in the western Elysium Basin) contains an assemblage of geomorphological features suggested to represent thermokarst and to be indicative of the thawing of ground ice, possibly within the last few million years (Balme et al., 2013). Shean (2010) has tentatively identified possible ice-rich fill in craters in the Sinus Sabaeus region at latitudes as low as $4^{\circ} \mathrm{S}$. If the sulphate-rich sedimentary strata traversed by Opportunity in equatorial Meridiani Planum represent a sublimation residue of a dusty ice-sheet, as proposed by Niles and Michalski (2009), then they too could be underlain by significant quantities of ancient ice. Mapping of MONS data shows no evidence of hydration in the Opportunity exploration area although $600 \mathrm{~km}$ further north in Meridiani Planum hydrogen enrichment has been attributed to the presence of hydrated minerals (Wilson et al., 2018); however, the coarse spatial resolution (hundreds of $\mathrm{km}$ ) of MONS mapping, even with the improved reconstruction methods employed by Wilson et al., would be inadequate to detect small residual pockets of ground ice. 
Page (2007) suggested that contemporary ground-ice thaw and consequent surface runoff may occur occasionally in low, near-equatorial latitudes on Mars, and considered that transient meltwater flowing for only a few hours per day might have been sufficient to erode a dendritic drainage system in the Cerberus Plains, where patterned ground offers evidence of geologically-young freeze-thaw processes. Under current conditions Meridiani Planum might experience two or three sols per Martian year when surface temperature and pressure would exceed the water triple point and permit transient melting of ground ice (Page, 2007: fig. 9). Laboratory experiments have demonstrated that ice melting at Martian atmospheric pressures results in boiling of metastable water or brine, leading to hybrid sediment transport processes involving both wet and dry mechanisms, with only small amounts of meltwater being needed to move sediment on slopes (Massé et al., 2016). Modelling of regolith-atmosphere interactions by Steele et al. (2017b) suggests that under present-day conditions in the vicinity of Gale Crater (latitude c. $\left.5^{\circ} \mathrm{S}\right)$ surface ice $(<1.0 \mu \mathrm{m}$ thick) and small amounts of subsurface ice to depths of a few $\mathrm{mm}$ can form in the early morning but sublime completely in the day. Surface ice therefore seems inadequate, in present conditions at low latitudes, to provide meltwater in sufficient quantity and duration to form even very small-scale erosional or depositional features, while pockets of old ground ice sealed in the regolith, perhaps occasionally coming into contact with the atmosphere through cracks opened by thermal expansion and contraction, might be a plausible source.

\subsection{Methane hydrates}

Intermittent localised decomposition of buried methane hydrates could potentially result in the surface release of meltwater (forming gutters) and methane gas (forming leveed fissures). Methane has been detected in the Martian atmosphere and its non-uniform distribution suggests localised sources and/or sinks (Formisano et al., 2004; Mumma et al., 2009). Page (2007) speculated about the existence of methane-water clathrates (methane hydrate), liable to decompose when depressurized but otherwise stable at all latitudes to the Martian equator, proposing that permafrost degradation might lead to clathrate release and the production of meltwater from ground ice. Very slow release of methane from buried clathrates may have occurred over billions of years, as erosion of overburden rendered them shallow enough to become depressurized and thermally destabilized by climatic warming intervals (PrietoBallasteros et al., 2006). Chassefière (2009) argued that micron-sized methane clathrate particles could remain metastable at depths of a few kilometres to a few metres below the Martian surface so that, having formed at high pressures deep within the crust, they could be released to the surface in small particulate form to decompose in the atmosphere. Subsurface clathrate layers formed at depth and high pressure could be put in contact with the atmosphere through deep bedrock fractures - for example around and beneath large impact craters.

Chassefière and Leblanc (2011) postulated the existence of water-ice and metastable methane in soil pore-space within $10 \mathrm{~m}$ of the surface, from where they could be released to the atmosphere.

\subsection{Liquid brines}

An alternative source of transient liquid could be the decomposition of a hydrated magnesium sulphate mineral $\left(\mathrm{MgSO}_{4} \cdot 11 \mathrm{H}_{2} \mathrm{O}\right)$ that is stable at low temperatures but melts above $2^{\circ} \mathrm{C}$ into epsomite $\left(\mathrm{MgSO}_{4} \cdot 7 \mathrm{H}_{2} \mathrm{O}\right)$ and water $\left(\mathrm{H}_{2} \mathrm{O}\right)(70 \%$ and $30 \%$ by volume respectively), leaving empty crystal molds in the enclosing sediment, like those seen in some bedrock strata on the Opportunity traverses (Peterson and Wang, 2006). Brief, localised warming of concentrations of such crystals could lead to the rapid release of fluid saturated with magnesium sulphate, which would form a surface residue as the water evaporated. Another mechanism (suggested by an anonymous reviewer) to expose such minerals to warming at the surface could be small-scale meteorite impacts. 
Finally, the possible existence of contemporary, transient gutter-forming liquid brines in equatorial regions on Mars is supported by recent temperature and relative humidity observations by the Mars Science Laboratory Curiosity in Gale Crater (Buenestado et al., 2015; Martín-Torres et al., 2015) where it has been postulated that perchlorate brines (e.g. from calcium perchlorate, $\left.\mathrm{Ca}\left(\mathrm{ClO}_{4}\right)_{2}\right)$ form by deliquescence (the absorption of water vapour by a solid crystalline phase to form a saturated liquid solution) during the night in the uppermost $5 \mathrm{~cm}$ of the soil and evaporate in the day. Metastable calcium chloride $\left(\mathrm{CaCl}_{2}\right)$ brines are implicated in the formation of water tracks in the McMurdo Dry Valley region of Antarctica and their formation by deliquescence could, in theory, exist in contemporary Martian soil at the MSL site in Gale Crater subject to seasonal and diurnal variations in atmospheric temperature and relative humidity (Gough et al., 2016). At the Curiosity landing site favourable night-time periods for deliquescence of up to two hours are postulated, reduced to under an hour at the Opportunity landing site (Pál and Kerezsturi, 2017).

\section{Implications for potential microbial contamination}

To address concerns that terrestrial micro-organisms unintentionally transported to Mars by spacecraft could contaminate the Martian environment, reviews have identified "Special Regions" where microbial life might survive and replicate, requiring stringent cleanliness precautions for landers and rovers visiting such regions (Rummel et al., 2014). Additionally, some areas are designated "Uncertain regions" where temperatures and the presence of water might allow microbial propagation, but the limitations of remotely sensed data preclude certainty about this. Since the surface features herein identified in Meridiani Planum are potentially indicative of at least transient water availability and habitable temperatures in the shallow subsurface, consideration should be given to designating it an Uncertain Region pending further study, especially in view of Rummel et al.'s (2014) contention that no spacecraft that have so far landed on Mars were clean enough to enter a Special Region.

\section{Conclusion}

Leveed fissures and gutters in Meridiani Planum are relatively young features, probably no older than c. 50 kyrs. They may provide geomorphological evidence of recent (even contemporary) transient processes that would be extremely difficult for Mars rovers to observe directly, involving gases and liquids formed by the sublimation of $\mathrm{CO}_{2}$ frost, melting and/or sublimation of ground ice, dissociation of buried methane clathrates, decomposition of hydrated magnesium sulphate or the formation of liquid brines by deliquescence of calcium chloride or calcium perchlorate. Dry granular flow mechanisms proposed as explanations for RSL seem inadequate to explain the morphologies of leveed fissures and gutters. Although such interpretations can only be speculative at present, their potential indications of habitable subsurface environments for terrestrial microbiota introduced by landers suggest a need for further investigation.

\section{Acknowledgments}

I am grateful to Ken Herkenhoff (USGS, Flagstaff) and James Head (Brown University) for their encouragement and helpful critical comments on draft versions of the manuscript. I thank the two anonymous reviewers for their critical comments and suggestions which have resulted in substantial and beneficial revisions. 


\section{References}

Aharonson, O., Schorghofer, N., 2006. Subsurface ice on Mars with rough topography. Journal of Geophysical Research 111, E11007.

Balme, M.R., Gallagher, C.J., Hauber, E., 2013. Morphological evidence for geologically young thaw of ice on Mars: A review of recent studies using high-resolution imaging data. Progress in Physical Geography 37, 289-324.

Balme, M.R., Gallagher, C.J., Pages, D.P., Murray, J.B., Muller, J.-P., Kim, J.-R., 2010. The Western Elysium Planitia palaeolake, in: Cabrol, N.A., Grin, E.A. (Eds.), Lakes on Mars. Elsevier, pp. 275-305.

Buenestado, J.F., Zorzano, M.P., Martín-Torres, J., 2015. Liquid water at Crater Gale, Mars. Astrobiology and Outreach 3, 131.

Burr, D.M., Soare, R.J., Tseung, J.-M. W.B., Emery, J.P., 2005. Young (late Amazonian), nearsurface, ground ice features near the equator, Athabasca Valles, Mars. Icarus 178, 56-73.

Carr, M., 2006. The surface of Mars. Cambridge Planetary Science Series, Cambridge University Press, xiv + 307 pp.

Chassefière, E., 2009. Metastable methane clathrate particles as a source of methane to the Martian atmosphere. Icarus 20, 137-144.

Chassefière, E., Leblanc, F., 2011. Methane release and the carbon cycle on Mars. Planetary and Space Science 59, 207-217.

Dundas, C.M., Keszthelyi, L.P., Bray, V. J., McEwen, A.S., 2010. Role of material properties in the cratering record of young platy-ridged lava on Mars. Geophysical Research Letters 37, L12203.

Formisano, V., Atreya, S., Encrenaz, T., Ignatiev, N., Giuranna, M. 2004. Science 306, 17581761.

Golombek, M., Robinson, K., McEwen, A., Bridges, N., Ivanov, B., Tornabene, L., Sullivan, R., 2010. Constraints on ripple migration at Meridiani Planum from Opportunity and HiRISE observations of fresh craters. Journal of Geophysical Research 115, E00F08. doi: 10.1029/2010JE003628.

Gough, R.V., Chevrier, V.F., Tolbert, M.A., 2016. Formation of liquid water at low temperatures via the deliquescence of calcium chloride: Implications for Antarctica and Mars. Planetary and Space Science 131, 79-87.

Gourronc, M., Bourgeois, O., Mège, D., Podchat, S., Bultel, B., Massé, M., Le Deit, L., Le Muélic, S., Mercier, D., 2014. One million cubic kilometers of fossil ice in Valles Marineris: Relicts of a 3.5 Gy old glacial landsystem along the Martian equator. Geomorphology 204, 235-255.

Head, J.W., Marchant, D.R., Kreslavsky, M.A., 2008. Formation of gullies on Mars: Link to recent climate history and insolation microenvironments implicate surface water flow origin. PNAS 104, 13258-13263.

Head, J.W., Neukum, G., Jaumann, R., Hiesinger, H., Hauber, E., Carr, M., Masson, P., Foing, B., Hoffmann, H., Kreslavsky, M., Werner, S., Milkovich, S., van Gasselt, S., The HRSC Co-Investigator Team, 2005. Tropical to mid-latitude snow and ice accumulation, flow and glaciation on Mars. Nature 434: 346-351.

Hecht, M.H., 2002. Metastability of liquid water on Mars. Icarus 156, 373-386.

Hecht, M.H., Vasavada, A.R., 2006. Transient liquid water near an artificial heat source on Mars. Mars 2, 83-96.

Horne, D.J., 2005. In the Land of the Meridian: fieldwork on Mars. Geology Today 21, 27-32.

Jakosky, B.M., Mellon, M.T., Varnes, E.S., Feldman, W.C., Boynton, W.V., Haberle, R.M., 2005. Mars low-latitude neutron distribution: Possible remnant near-surface water ice and a mechanism for its recent emplacement. Icarus 175, 58-67.

Kocurek, G., Ewing, R.C., 2012. Source-to-sink. An Earth/Mars comparison of boundary conditions for eolian dune systems, in: Grotzinger, J.P., Milliken, R.E. (Eds.).

Sedimentary Geology of Mars, SEPM Special Publication No. 102, pp. 151-168.

Levin, R.L., Weatherwax, J.L., 2004. Liquid water on Mars, in: Hoover, R.B., Rozanov, A.Y. (Eds.). Instruments, Methods, and Missions for Astrobiology VII, SPIE Proceedings 5163, pp. 145-157. 
Levy, J.S., Head, J.W., Marchant, D.R., 2008. The role of thermal contraction crack polygons in cold-desert fluvial systems. Antarctic Science 20, 565-579.

Levy, J.S., Head, J.W., Marchant, D.R., Dickson, J.L., Morgan, G.A., 2009. Geologically recent gully-polygon relationships on Mars: Insights from the Antarctic Dry Valleys on the roles of permafrost, microclimates, and water sources for surface flow. Icarus 201, 113-126.

McEwen, A.S., Ojha, L., Dundas, C.M., Mattson, S.S., Byrne S., Wray, J.J., Cull, S.C., Murchie, S.L., Thomas, N., Gulick, V.C. 2011. Seasonal flows on warm Martian slopes. Science 333, 740-743.

McEwen, A.S., Dundas, C.M., Mattson, S.S., Toigo, A.D., Ojha, L., Wray, J.J., Chojnacki, M., Byrne S., Murchie, S., Thomas, N. 2014. Recurring slope lineae in equatorial regions of Mars. Nature Geoscience 7, 53-58.

Mangold, N., 2011. Water ice sublimation-related landforms on Mars, in: Balme, M.R., Bargery, A.S., Gallagher, C.J., Gupta, S. (Eds.), Martian geomorphology. Geological Society, London, Special Publications 356, pp. 133-149.

Martín-Torres, F.J., Zorzano, M.-P., Valentin-Serrano, P., Harri, A.-M., Genzer, M., Kemppinen, O., Rivera-Valentin, E.G., Jun, I., Wray, J., Madsen, M.B., Goetz, W, McEwen, A.S., Hardgrove, C., Renno, N., Chevrier, V.F., Mischna, M., Navarro-González, R., MartínezFrías, J., Conrad, P., McConnochie, T., Cockell, C., Berger, G., Vasavada, A.R., Sumner, D., Vaniman, D., 2015. Transient liquid water and water activity at Gale Crater on Mars. Nature Geoscience 8, 357-361.

Massé, M., Conway, S.J., Gargani, J., Patel, M.R., Pasquon, K., McEwens, A., Carpy, S., Chevrier, V., Balme, M.R., Ojha, L., Vincendon, M., Poulet, F., Costard, F., Jouannic, G. 2016. Transport processes induced by metastable boiling water under Martian surface conditions. Nature Geoscience 9, 425-429.

Mumma, M.J., Villanueva, G.L., Novak, R.E., Hewagama, T., Bonev, B.P., DiSanti, M.A., Smith, M. D. 2009. Strong release of methane on Mars in northern summer 2003. Science 323, 1041-1045.

Murray, J.B., 2005. Evidence from the Mars Express High Resolution Camera for a frozen sea close to Mars' equator. Nature 434, 352-356.

Niles, P.B., Michalski, J., 2009. Meridiani Planum sediments on Mars formed through weathering in massive ice deposits. Nature Geoscience 2, 219-220.

Ohja, L., Wilhelm, M.B., Murchie, S., McEwen, A.S., Wray, J.J., Hanley, J., Massé, M., Chojnacki, M. 2015. Spectral evidence for hydrated salts in recurring slope lineae on Mars. Nature Geoscience 8, 829-832.

Page, D.P., 2007. Recent low-latitude freeze-thaw on Mars. Icarus 189, 83-117.

Pál, B., Kereszturi, A., 2017. Possibility of microscopic liquid water formation at landing sites on Mars and their observational potential. Icarus 282, 84-92.

Peterson, R.C., Wang, R., 2006. Crystal molds on Mars: Melting of a possible new mineral species to create Martian chaotic terrain. Geology 34, 957-960.

Piqueux, S., Kleinböhl, A., Hayne, P.O., Heavens, N.G., Kass, D.M., McCleese, D.J., Schofield, J.T., Shirley, J.H., 2016. Discovery of a widespread low-latitude diurnal $\mathrm{CO}_{2}$ frost cycle on Mars. Journal of Geophysical Research 121, 1174-1189.

Prieto-Ballesteros, O., Kargel, J.S., Fairén, A.G., Fernández-Remolar, D.C., Dohm, J.M., Amils, R., 2006. Interglacial clathrate destabilization on Mars: Possible contributing source of its atmospheric methane. Geology 34, 149-152.

Rummell, J.D., Beaty, D.W., Jones, M.A., Bakermans, C., Barlow, N.A., Boston, P.J., Chevrier, V.F., Clark, B.C., de Vera, J.-P.P., Gough, R.V., Hallsworth, J.E., Head, J.W., Hipkin, V.J., Kieft, T.L., McEwen, A.S., Mellon, M.T., Mikucki, J.A., Nicholson, W.L.,Omelon, C.R., Peterson, R., Roden, E.E., Sherwood, B., Tanaka, K.L., Viola, D., Wray, J.J., 2014. A New Analysis of Mars "Special Regions": Findings of the Second MEPAG Special Regions Science Analysis Group (SR-SAG2). Astrobiology 14, 887-968.

Schmidt, F., Andrieu, F., Costard, F. Kocifaj, M., Merescu, A.G. 2017. Formation of recurring slope lineae on Mars by rarefied gas-triggered granular flows. Nature Geoscience 10, 270-274.

Schorghofer, N., Aharonson, O., 2005. Stability and exchange of subsurface ice on Mars. Journal of Geophysical Research 110, E05003. 
Shean, D.E., 2010. Candidate ice-rich material within equatorial craters on Mars. Geophysical Research Letters 37, L24202. doi: 10.1029/2010GL045181.

Shinbrot, T., Duong, N.-H., Kwan, L., Alvarez, M.M., 2004. Dry granular flows can generate surface features resembling those seen in Martian gullies. PNAS 101, 8542-8546.

Smoluchowksi, R., 1968. Mars: retention of ice. Science 159, 1348-1350.

Steele, L.J., Balme, M.R., Lewis, S.R. 2017a. Regolith-atmosphere exchange of water in Mars' recent past. Icarus 284, 233-248.

Steele, L.J., Balme, M.R., Lewis, S.R., Spiga, A. 2017b. The water cycle and regolithatmosphere interaction at Gale crater, Mars. Icarus 289, 56-79.

Vincendon, M., Mustard, J., Forget, F., Kreslavsky, M., Spiga, A., Murchie, S., Bibring, J.-P., 2010. Near-tropical subsurface ice on Mars. Geophysical Research Letters 37, L01202.

Wilson, J.T., Eke, V.R., Massey, R.J., Elphic, R.C., Feldman, W.C., Maurice, S., Teodoro, L.F.A., 2018. Equatorial locations of water on Mars: improved resolution maps based on Mars Odyssey Neutron Spectrometer data. Icarus 299, 148-160. 


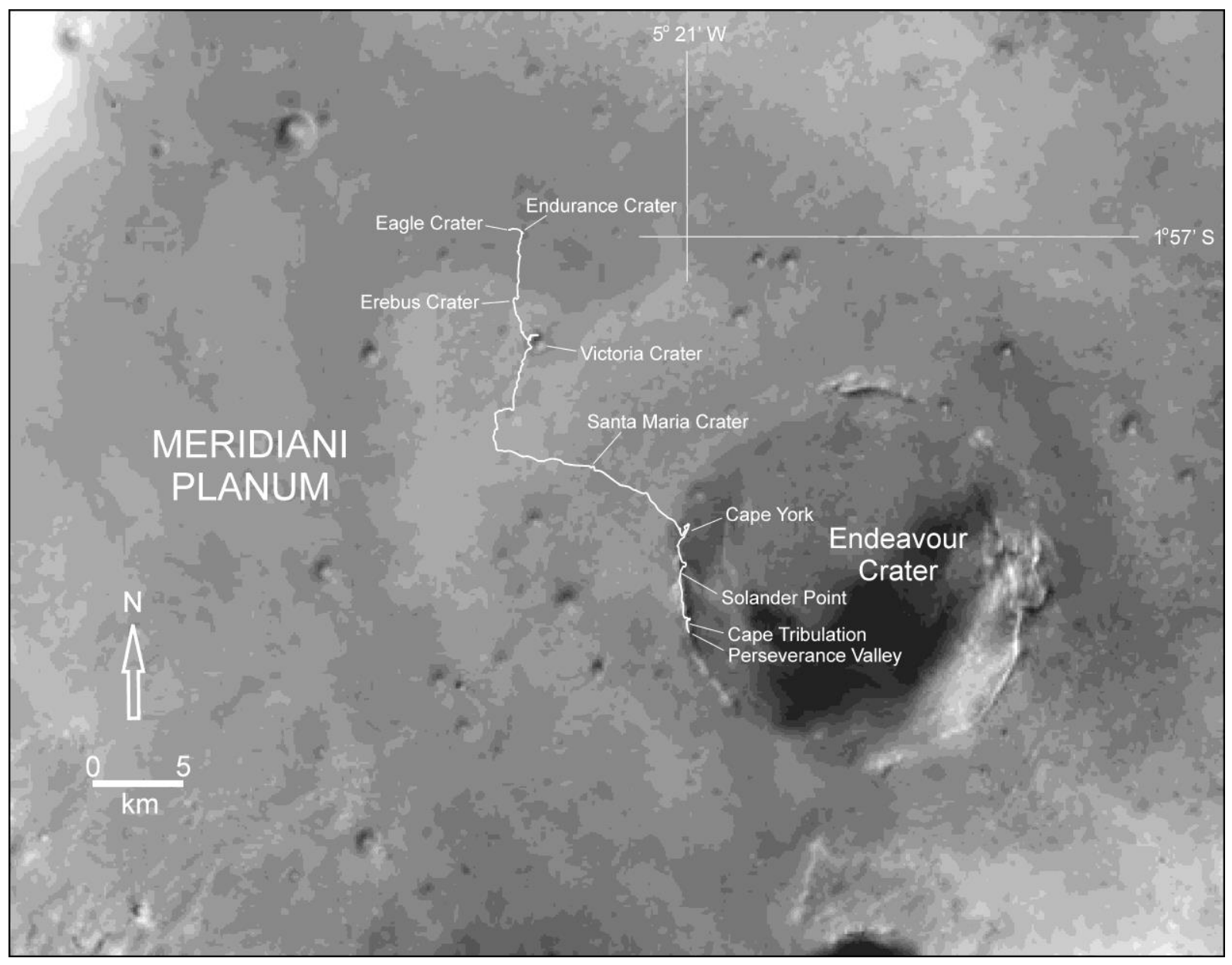

Fig. 1. Annotated Mars Reconnaissance Orbiter image showing the route explored in Meridiani Planum by the MER Opportunity between sols 1 (Eagle Crater) and 4720 (Perseverance Valley). Image (Context Camera Mosaic, $18^{\text {th }}$ March 2009) by courtesy of NASA/JPL-Caltech/MSSS. 


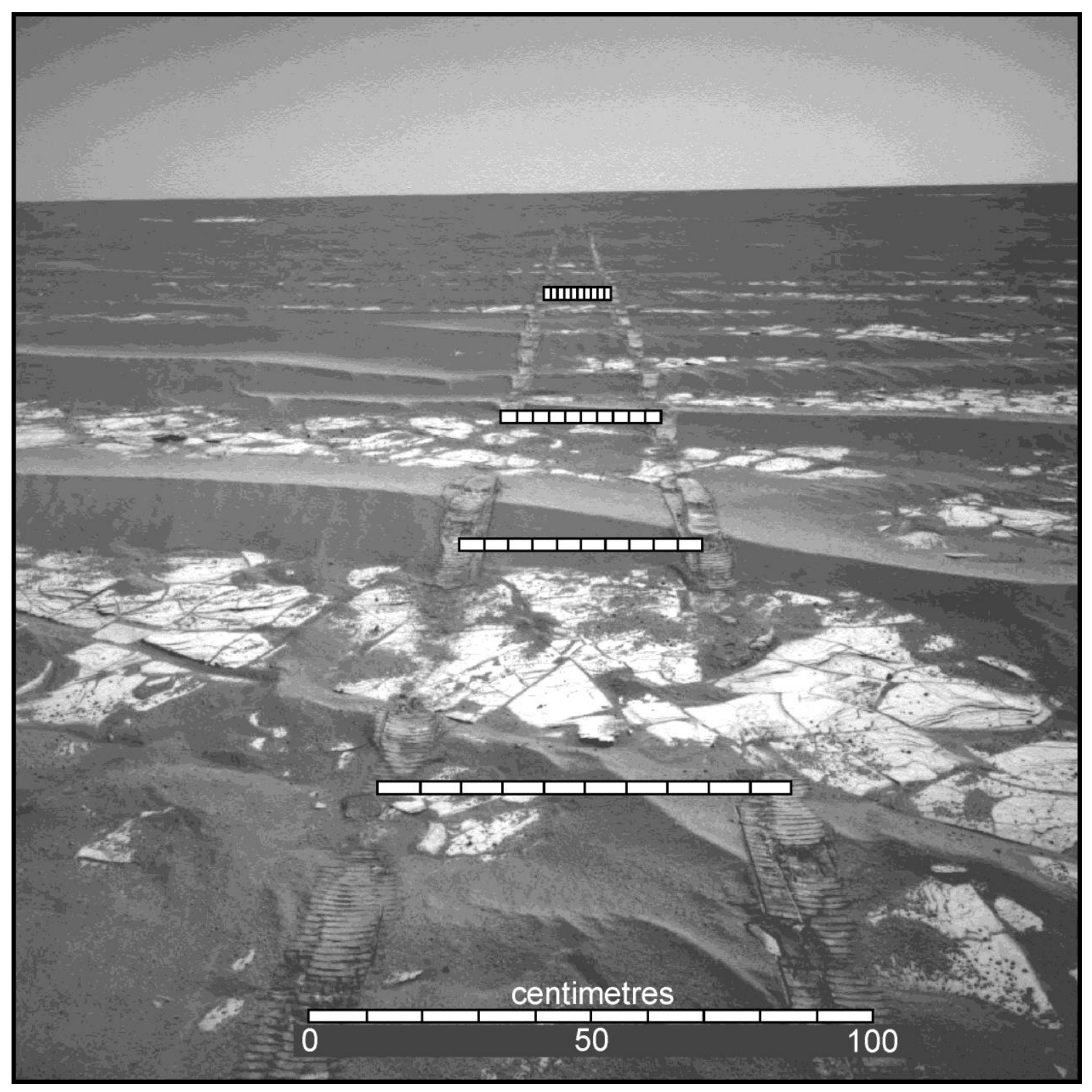

Fig. 2. Scale bars (1 m with $10 \mathrm{~cm}$ graduations) applied to a NavCam image showing MER wheel tracks across sand ripples (dark) and exposed bedrock (light) in Meridiani Planum (Sol 2336, 1N335563002EFFAONOP1925LOM1). 


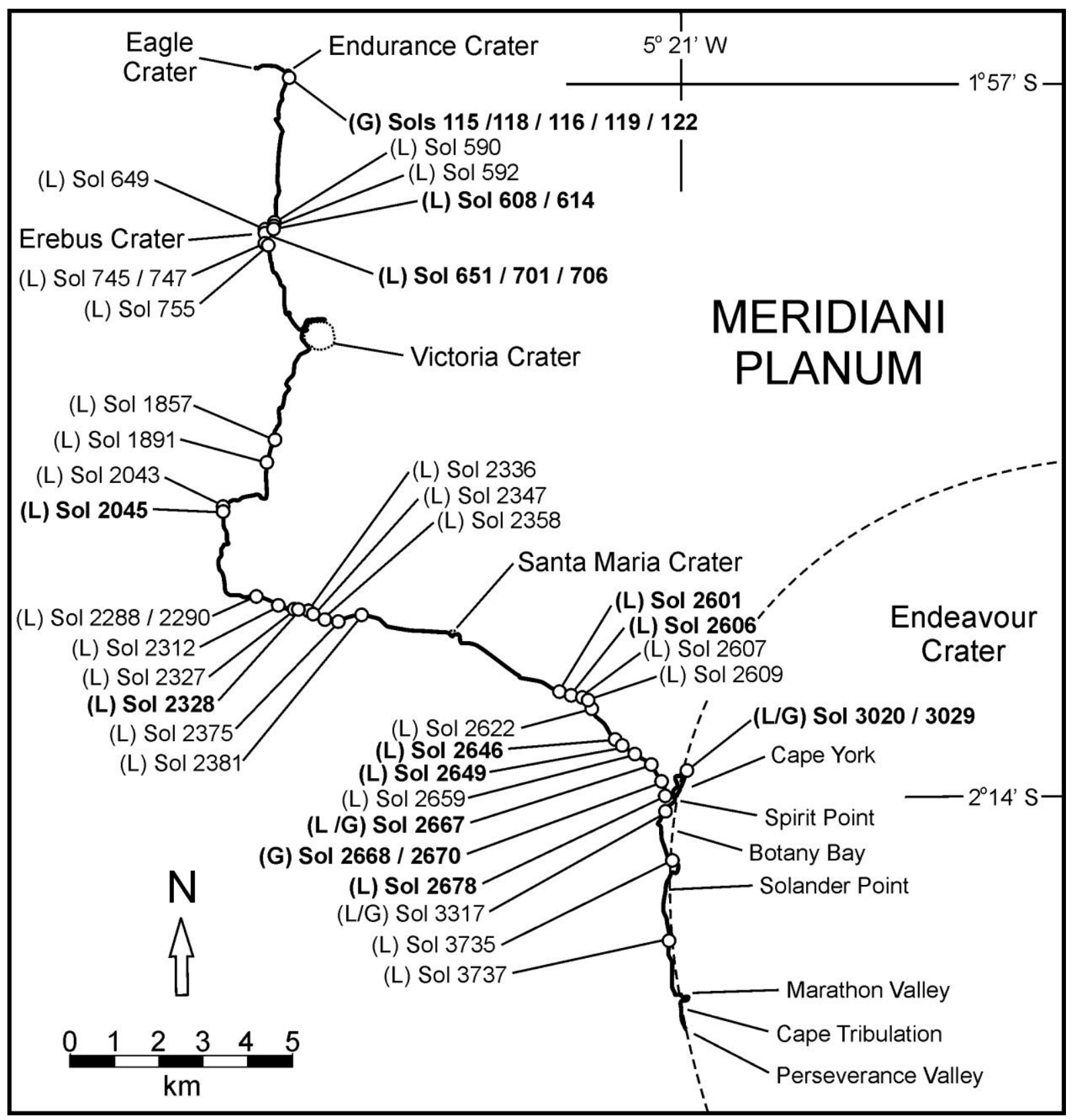

Fig. 3. Map showing route traversed by Opportunity from landing in Eagle Crater $\left(25^{\text {th }}\right.$ January 2004, Sol 1) to reaching Perseverance Valley on the rim of Endeavour Crater $\left(5^{\text {th }}\right.$ November 2017, Sol 4720); circles and sol numbers mark sites where leveed fissures (L) or gutters (G) were imaged (see Table 1), with sol numbers in bold for examples figured herein. 


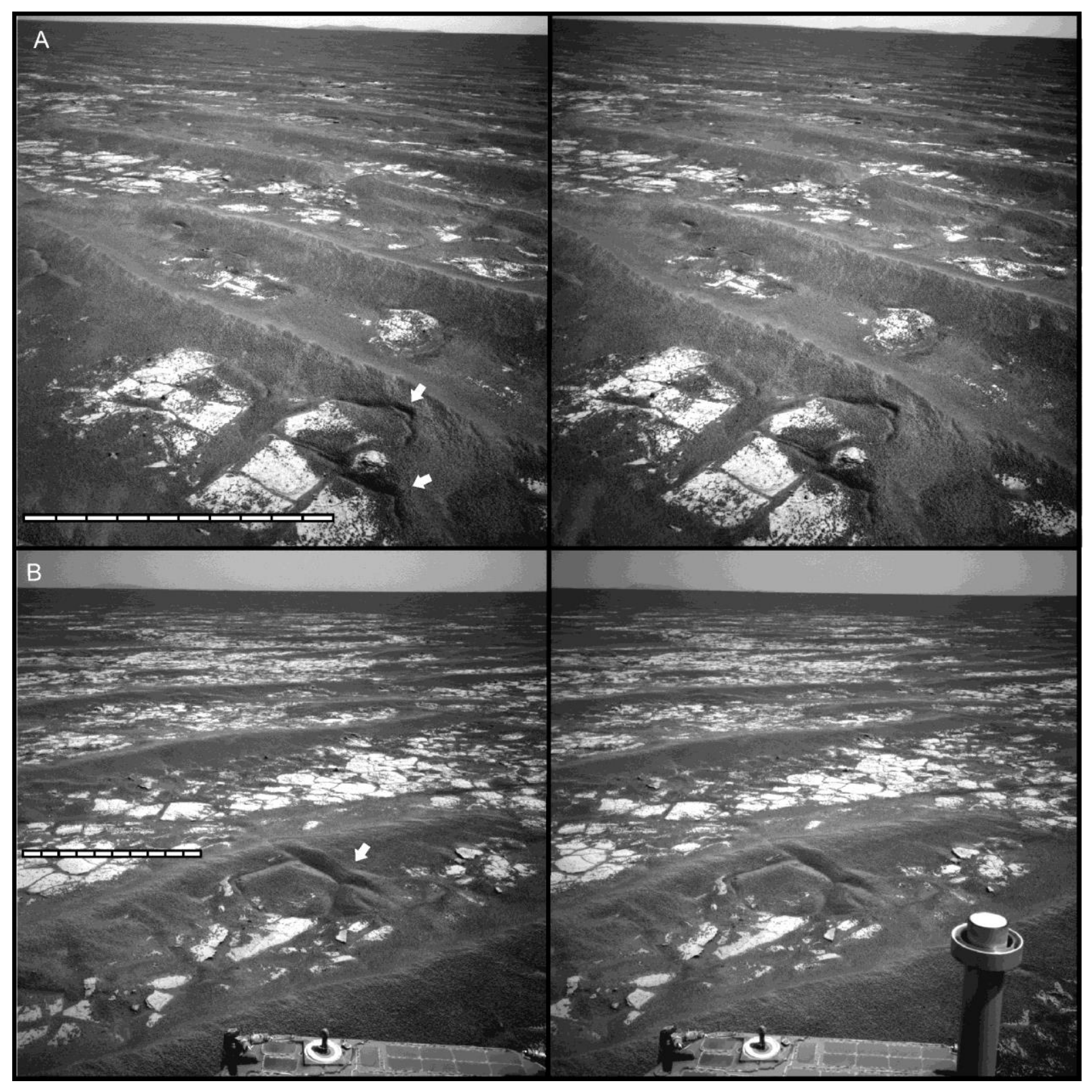

Fig. 4. A: leveed fissures (arrowed) apparently coincident with underlying bedrock fractures, showing levees of dark soil superimposed on light-toned bedrock, and cutting the flank of an aeolian ripple (Sol 2646, c. $2 \mathrm{~km}$ outside the western rim of Endeavour crater, uncropped stereo-pair (1N363080749EFFBFT3P1777L0M1, 1N363080749EFFBFT3P1777R0M1); B: bifurcating leveed fissures (arrowed) cross-cutting a ripple crest (Sol 2649, c. $2 \mathrm{~km}$ outside the western rim of Endeavour crater, uncropped stereo-pair (1N363356561EFFBG00P0673L0M1, 1N363356561EFFBG00P0673R0M1). Scale bars $1 \mathrm{~m}$ with $10 \mathrm{~cm}$ graduations. All images by courtesy of NASA/JPL-Caltech. 


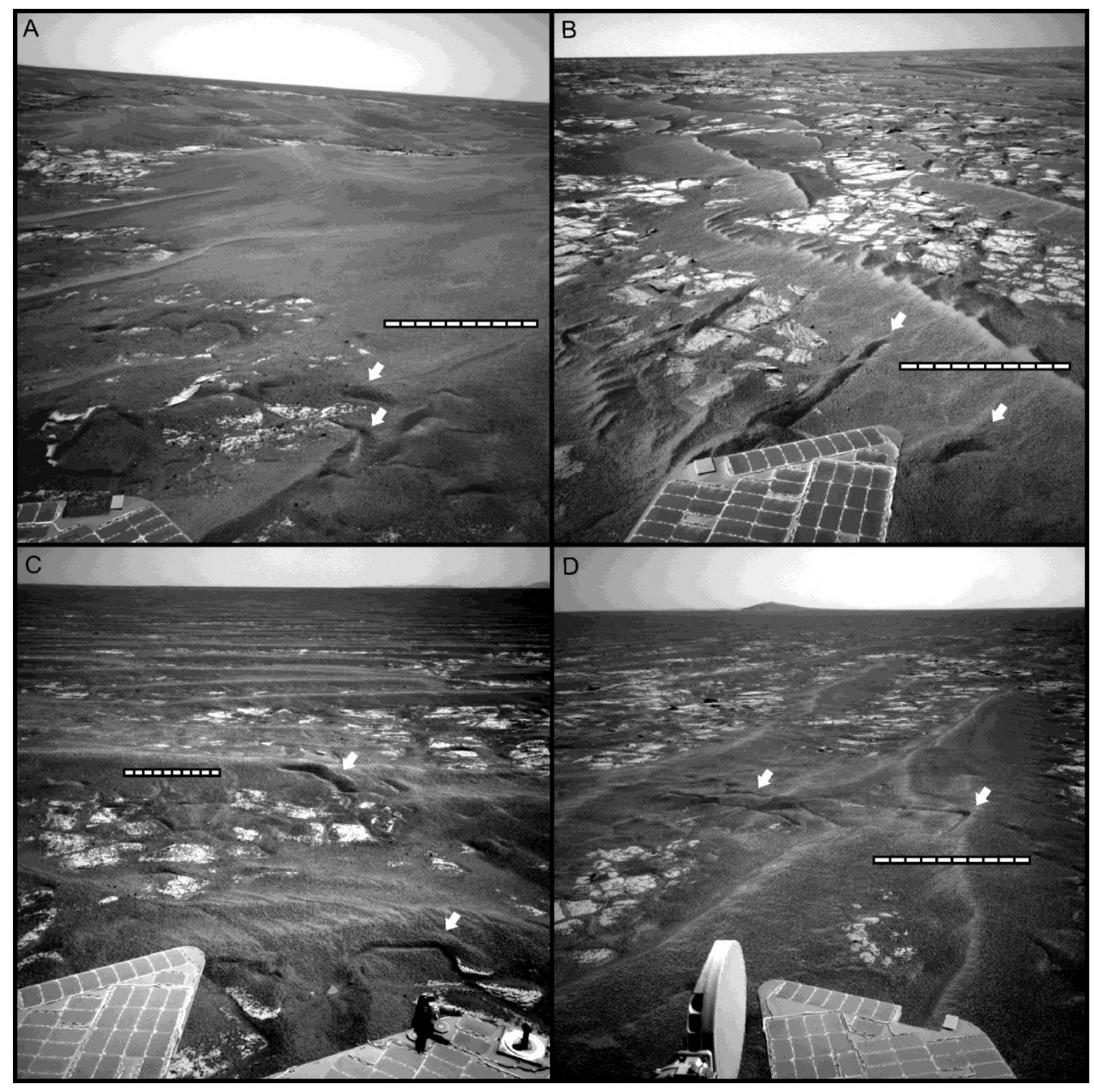

Fig. 5. Leveed fissures (arrowed) cross-cutting aeolian ripples. A: vicinity of Erebus crater, Sol 747 (1N194501483EFF645NP1824R0M1); B: approx. $6 \mathrm{~km}$ south of Victoria crater, Sol 2328 (1N334858666EFFANLYP1777L0M1); C: approx. $3 \mathrm{~km}$ outside western edge of Endeavour crater, Sol 2601 (1N359088373EFFB9YCP0653R0M1); D: approx. 3 km outside western edge of Endeavour crater, Sol 2606 (1N359543887EFFBA00P1957R0M1). All images uncropped. Scale bars $1 \mathrm{~m}$ with $10 \mathrm{~cm}$ graduations. All images by courtesy of NASA/JPL-Caltech. 


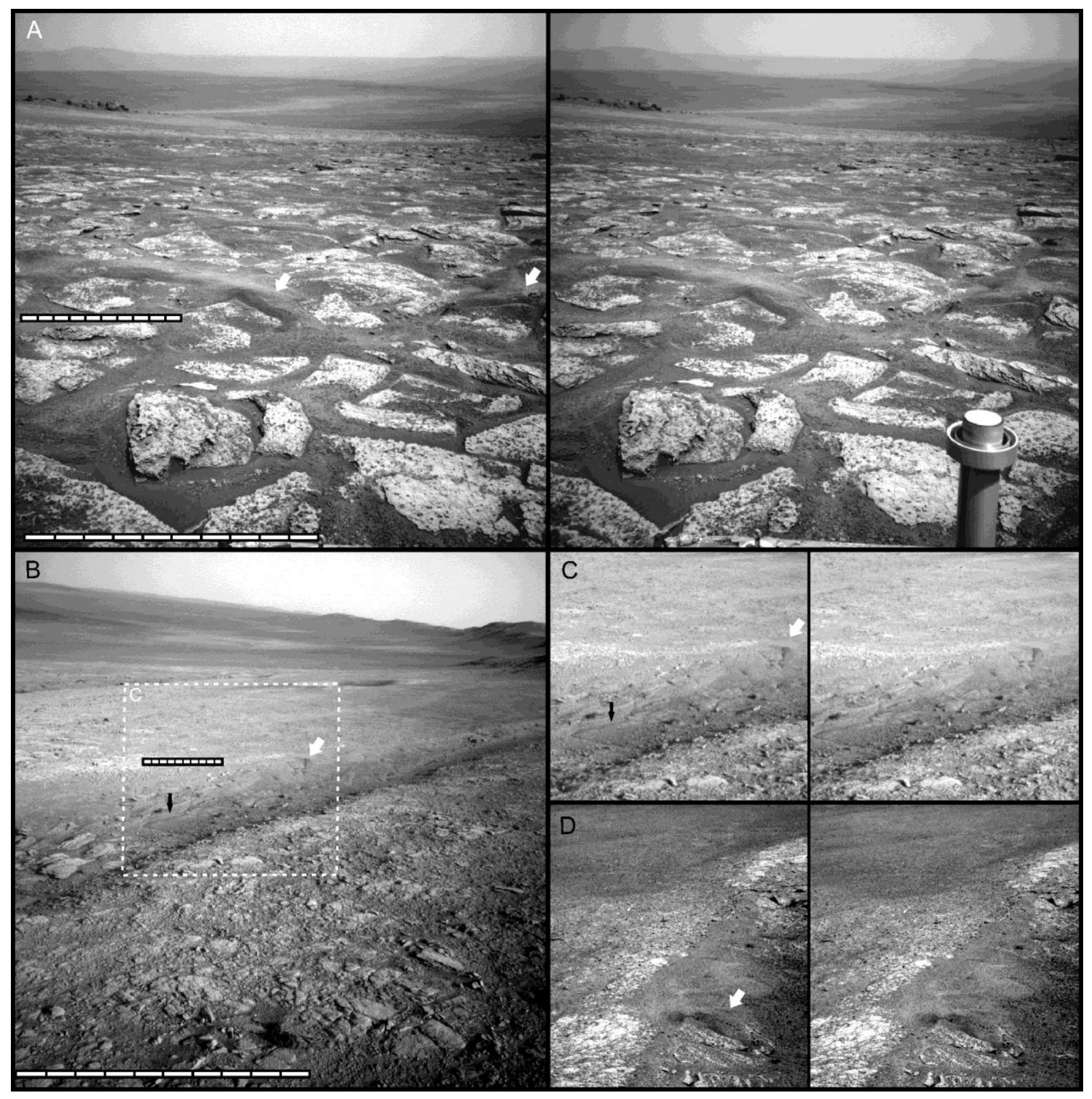

Fig. 6. A. Leveed fissures on western rim of Endeavour Crater, slope descending into the crater (Botany Bay), uncropped stereo-pair, Sol 2678 (1N365932318EFFBM00P1944L0M1, 1N365932318EFFBM00P1944R0M1); B-D: leveed fissure (white arrow) and gutters (black arrow) in a shallow gully (Whim Creek), inside the western rim of Endeavour Crater, uncropped image B: sol 3020 (1N396298228EFFBS00P1987L0M1); same as B (arrowed), cropped stereo pair, Sol 3020 (1N396298228EFFBS00P1987L0M1, 1N396298228EFFBS00P1987R0M1); D: same as $B$ viewed from different angle, cropped stereo pair, Sol 3029 (1P397081479EFFBU00P2376L2M1, 1P397081479EFFBU00P2376R2M1). Scale bars $1 \mathrm{~m}$ with $10 \mathrm{~cm}$ graduations. All images by courtesy of NASA/JPL-Caltech. 


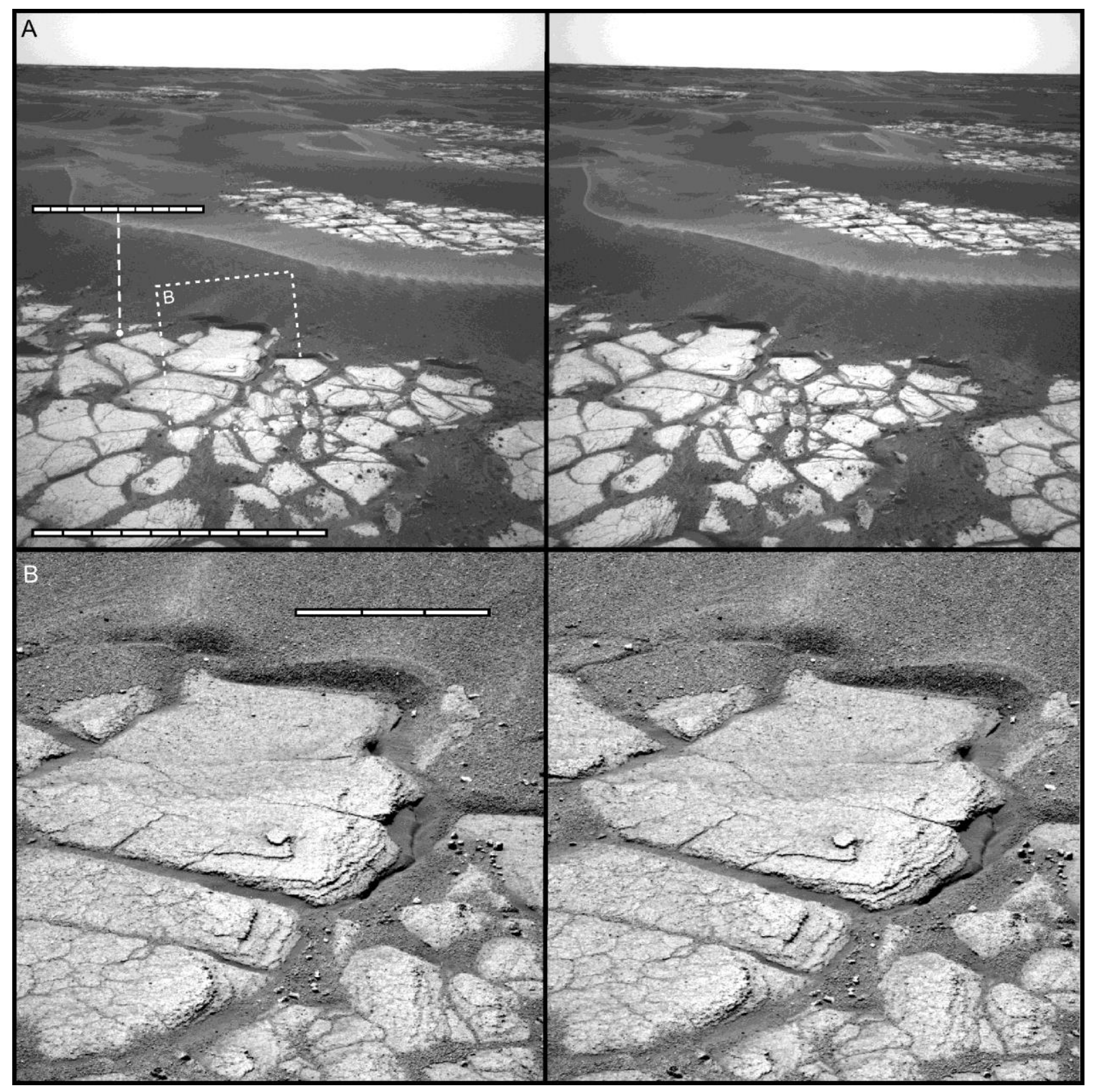

Fig. 7. Asymmetrical leveed fissures cutting lower slope of an aeolian ripple and around the edge of a bedrock slab, near northern rim of Erebus crater; A: uncropped stereo pair, Sol 608 (1N182164096EFF62JLP0755L0M1, 1N182164096EFF62JLP0755R0M1), scale bar $1 \mathrm{~m}$ with $10 \mathrm{~cm}$ graduations; B: uncropped stereo pair, Sol 614 (1P182694011ESF62JLP2544L7M1, Filter 7, $432 \mathrm{~nm}$ and 1P182694103ESF62JLP2544R1M1, Filter 1, $436 \mathrm{~nm}$ ), Scale bar $30 \mathrm{~cm}$ with $10 \mathrm{~cm}$ graduations. All images by courtesy of NASA/JPL-Caltech. 


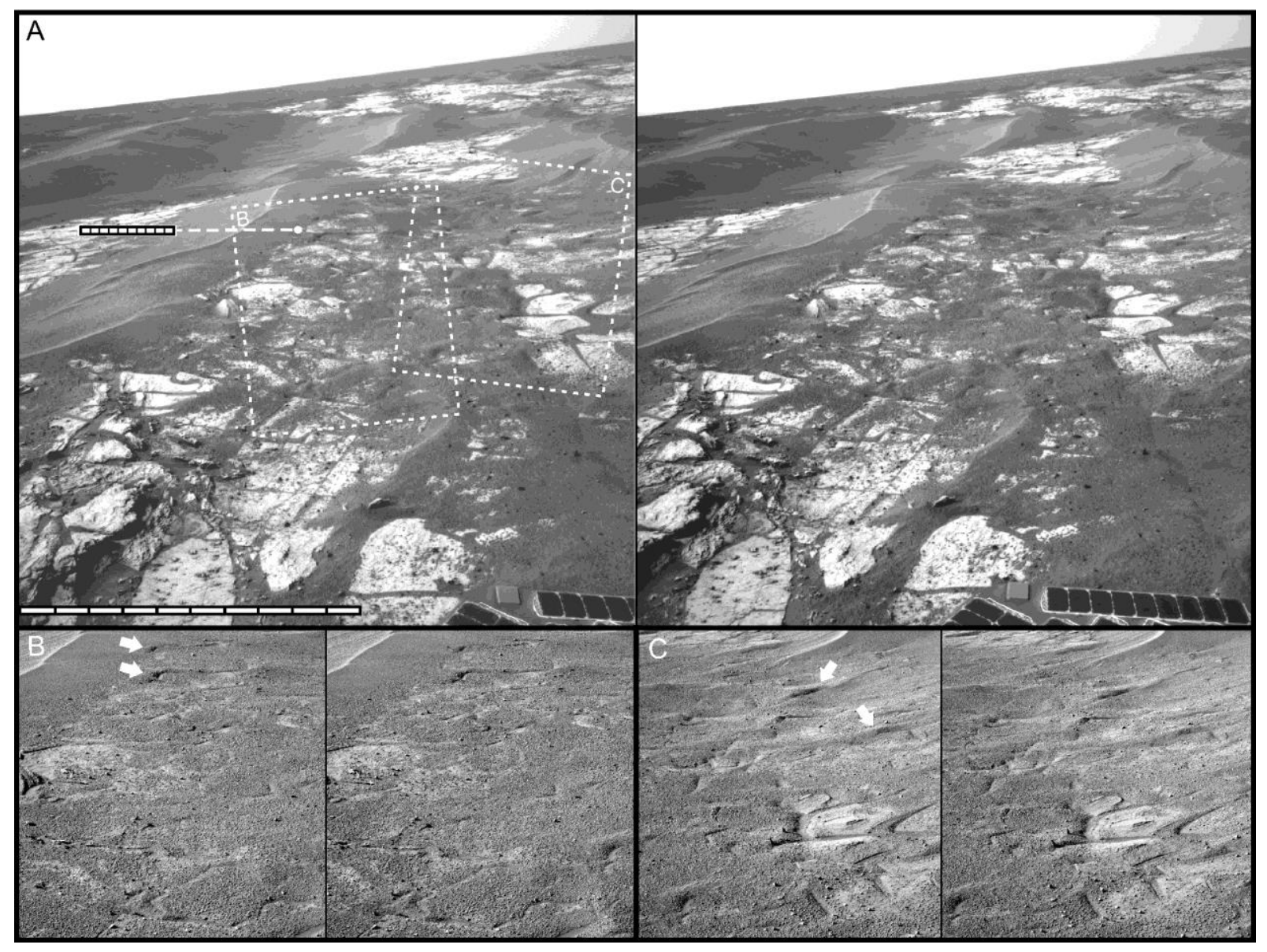

Fig. 8. Leveed fissure patterns disrupting aeolian ripple trough surfaces in Erebus crater; A: general view, uncropped stereo pair, Sol 651 (1N185987302EFF64KCP1925R0M1, 1N185987302EFF64KCP1925LOM1), scale bars $1 \mathrm{~m}$ with $10 \mathrm{~cm}$ graduations; B: detail (examples arrowed), uncropped stereo pair, Sol 701, 1P190430080EFF64KCP2437R1M1, 1P190430080EFF64KCP2437L7M1, both Filter 7, 432 nm); C: detail (examples arrowed), uncropped stereo pair, Sol 706 (1P190874207EFF64KCP2439L7M1, 1P190874207EFF64KCP2439R1M1, both Filter 7, $432 \mathrm{~nm})$. All images by courtesy of NASA/JPL-Caltech.

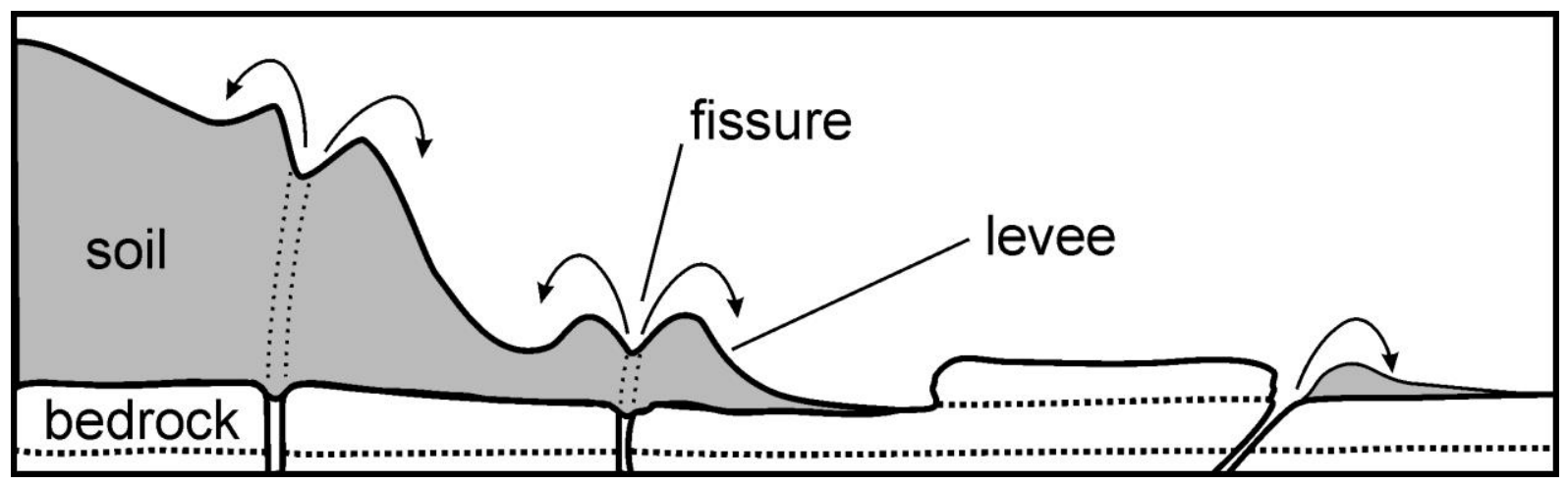

Fig. 9. Diagrammatic interpretation of leveed fissures (not to scale). 


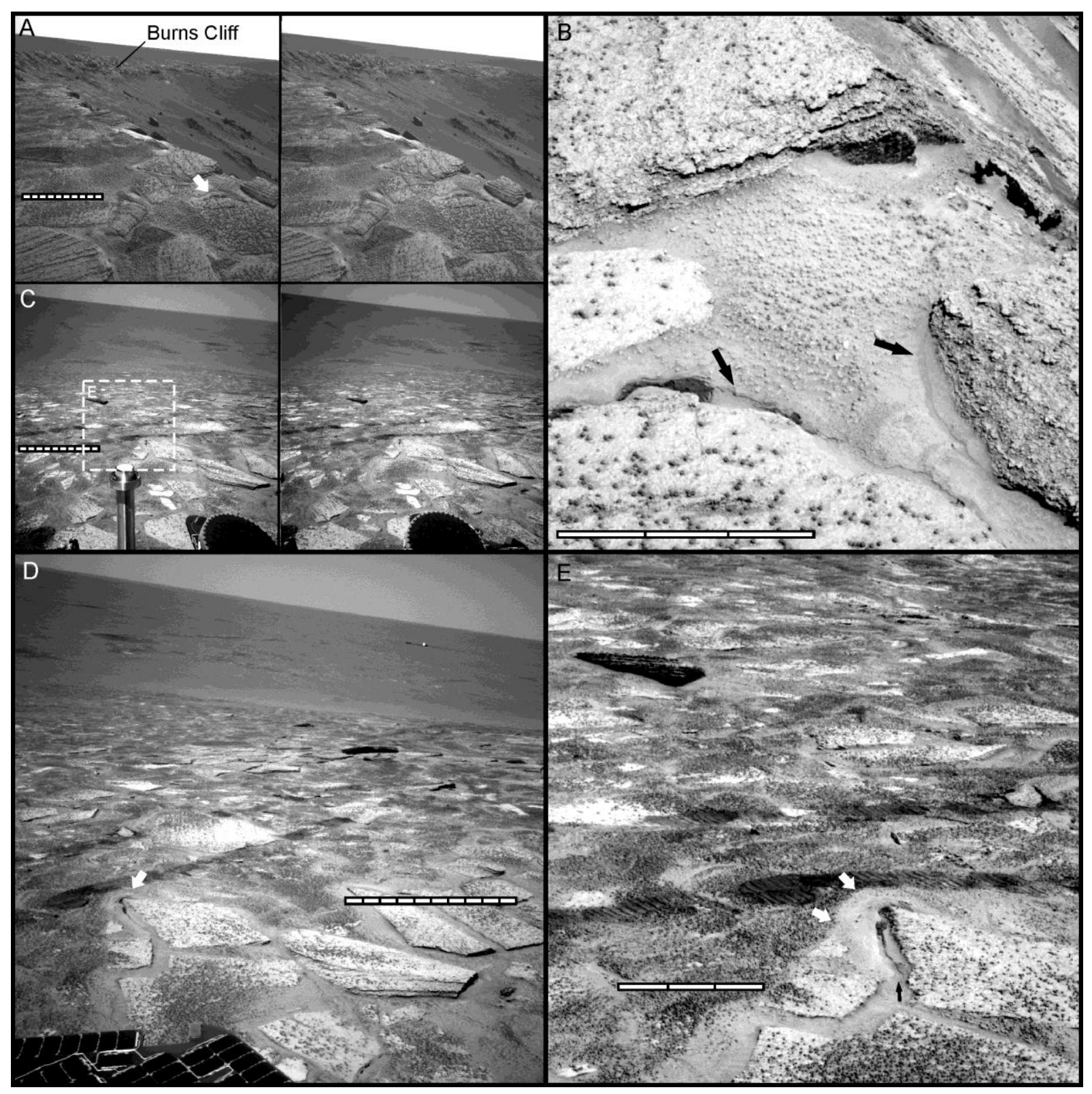

Fig. 10. A: Gutters (arrowed) on southern rim of Endurance crater, Sol 115, stereo pair (1N138404731EFF2800P1986L0M1, 1N138404731EFF2800P1986R0M1); B: close-up of gutters (arrowed) shown in A, Sol 118 (1P138654324EFF2809P2298L2M1 Filter 2, 754 nm); C$\mathrm{E}$ : gutter (arrowed) on outer slope of southern rim of Endurance crater (note dark MER wheel tracks running right to left beyond the gutter); C: stereo pair, Sol 119,

(1N138744884EFF2809P1987L0M1, 1N138744884EFF2809P1987R0M1); D: from different viewing angle, Sol 116 (1N138475971EFF2800P1987L0M1); E: from different viewing angle (white arrows indicate "collar" of fine, light-toned sediment, black arrow indicates long axis of gutter), Sol 122 (1P139018947EFF2809P2266R2M1 Filter 2, 754 nm).

Scale bars: A, C, D: $1 \mathrm{~m}$ with $10 \mathrm{~cm}$ graduations; B, E: $30 \mathrm{~cm}$ with $10 \mathrm{~cm}$ graduations. . All images uncropped. All images by courtesy of NASA/JPL-Caltech. 


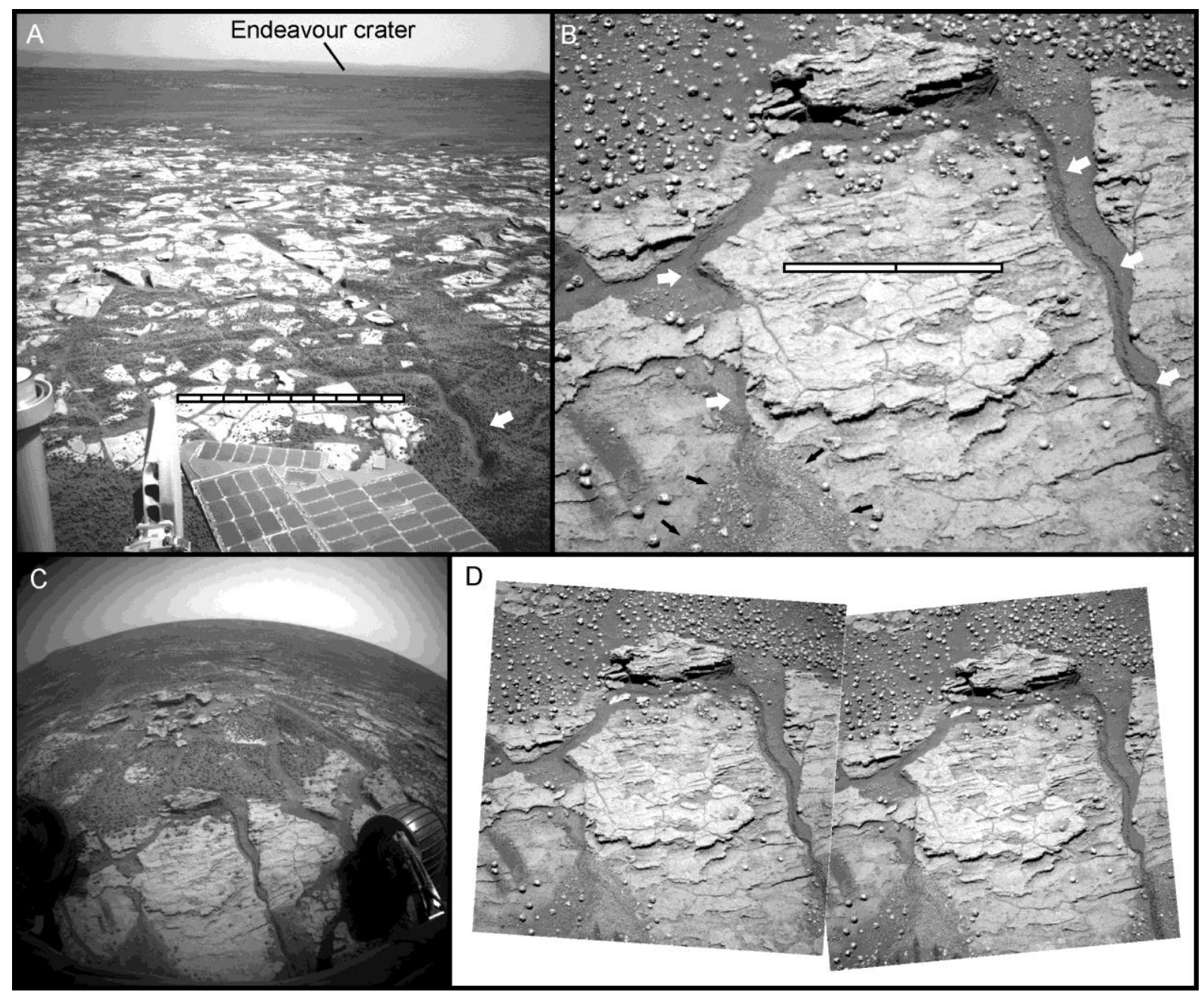

Fig. 11. A: leveed fissure (arrowed) connected to possible gutters or degraded (wind-softened?) fissure network, approx. $0.5 \mathrm{~km}$ outside western edge of Endeavour crater, uncropped image, Sol 2667 (1N364956838EFFBK00P0685L0M1), scale bar $1 \mathrm{~m}$ with $10 \mathrm{~cm}$ graduations; B-D: gutters approx. $0.5 \mathrm{~km}$ outside western edge of Endeavour crater; B: cropped image showing two gutters (white arrows) and a possible depositional fan (black arrows), Sol 2670 (1P365215925EFFBKN7P2573L7M1), scale bar $20 \mathrm{~cm}$ with $10 \mathrm{~cm}$ graduation; C: uncropped image, different viewing angle (note MER front wheels left and right), Sol 2668 (1F365046753EFFBKN5P1214R0M1); D: uncropped stereo-pair, Sol 2670 (1P365215925EFFBKN7P2573L7M1, 1P365215975EFFBKN7P2573R1M2). All images by courtesy of NASA/JPL-Caltech. 


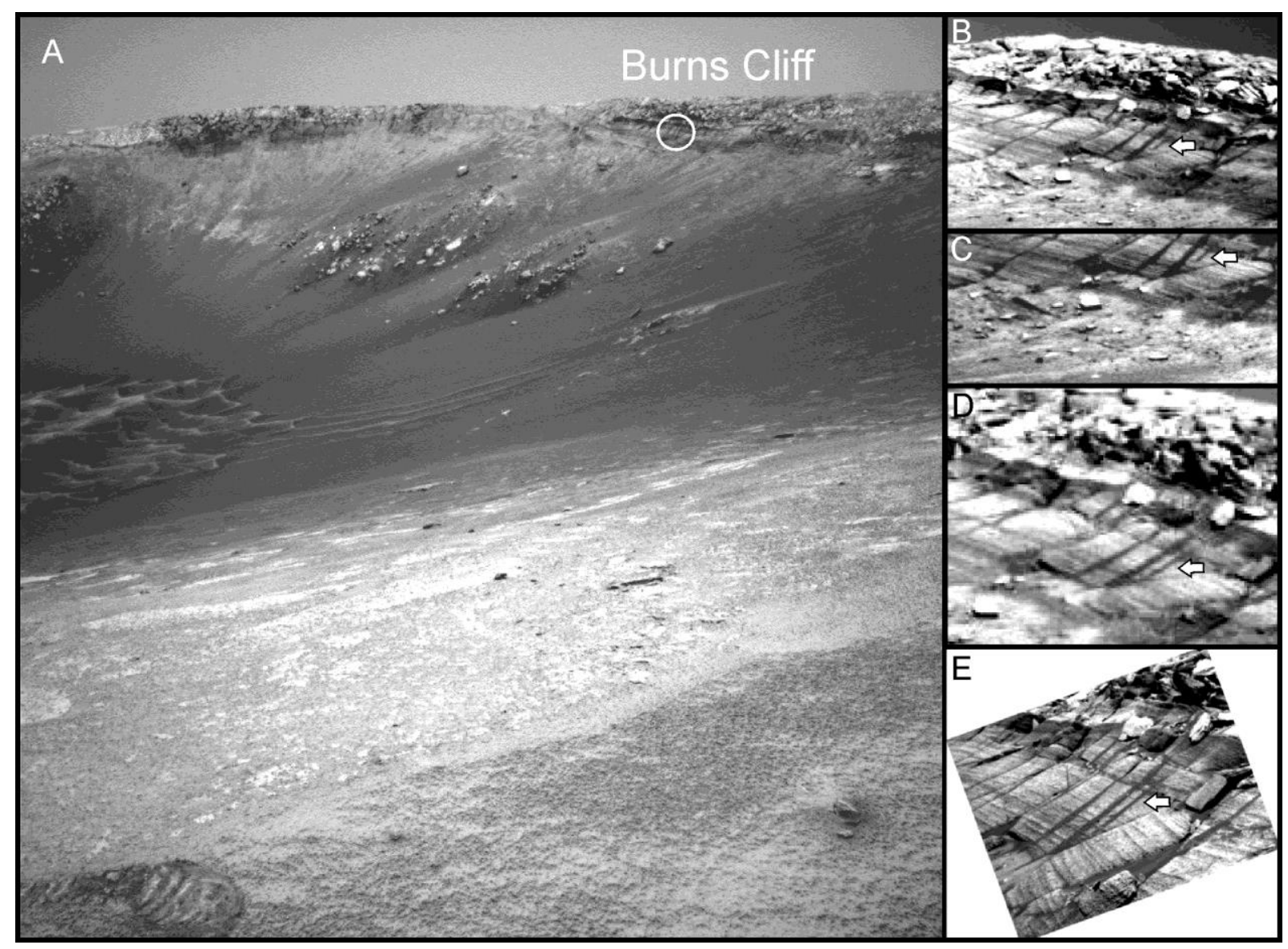

Fig. 12. Dark streaks on Burns Cliff in Endurance crater. A. uncropped view inside Endurance crater looking towards Burns Cliff, circled area (approx. $5 \mathrm{~m}$ diameter) indicates streaks shown in B-E, Sol 100 (1N137064893EFF2019P1903L0M1); B: cropped, Sol 262 (1N151450836EFF36DLP0882R0M1); C: cropped, Sol 263 (1N151534868EFF36F5P1981L0M1); D: cropped, Sol 268

(1N151981945EFF37B5P1909R0M1); E: cropped and rotated, Sol 280 1N153044518EFF37LJP1909R0M1); note that one streak (arrowed) extended further down the cliff between sols 263 and 268. All images by courtesy of NASA/JPL-Caltech. 
Table 1. Sites with leveed fissures and gutters observed in Meridiani Planum by the MER Opportunity.

\begin{tabular}{|c|c|c|c|c|}
\hline Sol & $\begin{array}{l}\text { Leveed } \\
\text { fissures }\end{array}$ & Gutters & $\begin{array}{c}\text { Selected images } \\
1 \mathrm{~F}=\text { Front HazCam } \quad 1 \mathrm{~N}=\text { NavCam }\end{array}$ & Figured \\
\hline 115 & & $\mathrm{x}$ & $\begin{array}{l}\text { 1N138404731EFF2800P1986LOM1 } \\
\text { 1N138404731EFF2800P1986R0M1 }\end{array}$ & Fig. $10 \mathrm{~A}$ \\
\hline 118 & & & 1P138654324EFF2809P2298L2M1 Filter 2 (754 nm) & Fig. 10B \\
\hline 116 & & & 1N138475971EFF2800P1987L0M1 & Fig. 10D \\
\hline 119 & & $\mathrm{x}$ & $\begin{array}{l}\text { 1N138744884EFF2809P1987L0M1 } \\
\text { 1N138744884EFF2809P1987R0M1 }\end{array}$ & Fig. 10C \\
\hline 122 & & & 1P139018947EFF2809P2266R2M1 Filter 2 (754 nm) & Fig. 10E \\
\hline 590 & $\mathrm{x}$ & & 1N180563297EFF60SEP1600L0M1 & - \\
\hline 592 & $\mathrm{x}$ & & 1N180739610EFF6200P0720L0M1 & - \\
\hline 608 & \multirow[b]{2}{*}{$\mathrm{x}$} & & $\begin{array}{l}\text { 1N182164096EFF62JLP0755L0M1 } \\
\text { 1N182164096EFF62JLP0755R0M1 }\end{array}$ & Fig. 7A \\
\hline 614 & & & $\begin{array}{l}\text { 1P182694011ESF62JLP2544L7M1 Filter } 7(432 \mathrm{~nm}) \\
\text { 1P182694103ESF62JLP2544R1M1 Filter } 1(436 \mathrm{~nm})\end{array}$ & Fig. 7B \\
\hline 649 & $\mathrm{x}$ & & 1N185808485EFF64I6P0705R0M1 & - \\
\hline 651 & \multirow{3}{*}{$\mathrm{x}$} & & $\begin{array}{l}\text { 1N185987302EFF64KCP1925R0M1 } \\
\text { 1N185987302EFF64KCP1925L0M1 }\end{array}$ & Fig. 8A \\
\hline 701 & & & $\begin{array}{l}\text { 1P190430080EFF64KCP2437R1M1 Filter } 7(432 \mathrm{~nm}) \\
\text { 1P190430080EFF64KCP2437L7M1 Filter } 7 \text { (432 nm) }\end{array}$ & Fig. 8B \\
\hline 706 & & & $\begin{array}{l}\text { 1P190874207EFF64KCP2439L7M1 Filter } 7(432 \mathrm{~nm}) \\
\text { 1P190874207EFF64KCP2439R1M1 Filter } 7(432 \mathrm{~nm})\end{array}$ & Fig. $8 \mathrm{C}$ \\
\hline 745 & $\mathrm{x}$ & & 1N194322112EFF643IP1657L0M1 & - \\
\hline 747 & $\mathrm{x}$ & & 1N194501483EFF645NP1824R0M1 & Fig. 5A \\
\hline 755 & $\mathrm{x}$ & & $\begin{array}{l}\text { 1N195212038EFF6500P0696LOM1 } \\
\text { 1N195212089EFF6500P0696LOM1 } \\
\text { 1N195212141EFF6500P0696L0M1 }\end{array}$ & - \\
\hline 1857 & $\mathrm{x}$ & & $\begin{array}{l}\text { 1N293041724EFF993ZP0695R0M1 } \\
\text { 1N293041909EFF993ZP1795R0M1 }\end{array}$ & - \\
\hline 1891 & $\mathrm{x}$ & & 1N296065242EFFA100P1979R0M1 & - \\
\hline 2043 & $\mathrm{x}$ & & 1N309555720EFFA8AXP0724R0M1 & - \\
\hline 2045 & $\mathrm{x}$ & & $\begin{array}{l}\text { 1N309731467EFFA8J0P0703L0M1 } \\
\text { 1N309731467EFFA8J0P0703R0M1 }\end{array}$ & - \\
\hline $\begin{array}{l}2288 \\
2290\end{array}$ & $\mathrm{x}$ & & $\begin{array}{l}\text { 1N331307542EFFAKFNP1991L0M1 } \\
\text { 1N331480515EFFAKFNP2873L0M2 }\end{array}$ & - \\
\hline 2312 & $\mathrm{x}$ & & 1N333433579EFFALS9P1767R0M1 & - \\
\hline 2327 & $\mathrm{x}$ & & 1N334770515EFFANDZP0653R0M1 & - \\
\hline \multirow{2}{*}{2328} & $\mathrm{x}$ & & 1N334857420EFFANLYP0673L0M1 & - \\
\hline & $\mathrm{x}$ & & 1N334858666EFFANLYP1777L0M1 & Fig. 5B \\
\hline 2336 & $\mathrm{x}$ & & 1N335562966EFFAONOP1925R0M1 & - \\
\hline 2347 & $\mathrm{x}$ & & 1N336549602EFFAP00P1991L0M1 & - \\
\hline \multirow{2}{*}{2358} & $\mathrm{x}$ & & 1N337525898EFFAQJLP1777R0M1 & - \\
\hline & $\mathrm{x}$ & & 1N337524810EFFAQJLP1777R0M1 & - \\
\hline 2375 & $\mathrm{x}$ & & 1N339033058EFFARUGP1757R0M2 & - \\
\hline 2381 & $\mathrm{x}$ & & 1N339567438EFFASIZP0643L0M1 & - \\
\hline 2595 & $\mathrm{x}$ & & 1N358560830EFFB8QOP1985R0M8 & - \\
\hline 2601 & $\mathrm{x}$ & & 1N359088373EFFB9YCP0653R0M1 & Fig. 5C \\
\hline 2606 & $\mathrm{x}$ & & 1N359543887EFFBA00P1957R0M1 & Fig. 5D \\
\hline 2607 & $x$ & & 1N359617908EFFBA00P1963R0M1 & - \\
\hline 2609 & $\mathrm{x}$ & & 1N359791912EFFBA09P1994L0M1 & - \\
\hline 2622 & $\mathrm{x}$ & & 1N360959976EFFBBOEP0683L0M1 & - \\
\hline 2646 & $\mathrm{x}$ & & $\begin{array}{l}\text { 1N363080749EFFBFT3P1777L0M1 } \\
\text { 1N363080749EFFBFT3P1777R0M1 }\end{array}$ & Fig. 4A \\
\hline 2649 & $\mathrm{x}$ & & $\begin{array}{l}\text { 1N363356561EFFBG00P0673LOM1 } \\
\text { 1N363356561EFFBG00P0673R0M1 }\end{array}$ & Fig. 4B \\
\hline 2659 & $\mathrm{x}$ & & 1N364239284EFFBHUYP0673L0M1 & - \\
\hline 2667 & $\mathrm{x}$ & $\mathrm{x}$ & 1N364956838EFFBK00P0685L0M1 & Fig. 11A \\
\hline 2668 & & \multirow[b]{2}{*}{$\mathrm{x}$} & 1F365046753EFFBKN5P1214R0M1 & Fig. 11C \\
\hline 2670 & & & $\begin{array}{l}\text { 1P365215925EFFBKN7P2573L7M1 } \\
\text { 1P365215975EFFBKN7P2573R1M2 }\end{array}$ & Fig.11B,D \\
\hline 2678 & $\mathrm{x}$ & & $\begin{array}{l}\text { 1N365932318EFFBM00P1944LOM1 } \\
\text { 1N365932318EFFBM00P1944R0M1 }\end{array}$ & Fig. $6 \mathrm{~A}$ \\
\hline 3020 & \multirow[b]{2}{*}{$\mathrm{x}$} & \multirow[b]{2}{*}{$\mathrm{x}$} & $\begin{array}{l}\text { 1N396298228EFFBS00P1987LOM1 } \\
\text { 1N396298228EFFBS00P1987R0M1 }\end{array}$ & Fig. 6B,C \\
\hline 3029 & & & $\begin{array}{l}\text { 1P397081479EFFBU00P2376L2M1 } \\
\text { 1P397081479EFFBU00P2376R2M1 }\end{array}$ & Fig. 6D \\
\hline 3317 & $x$ & $x$ & 1N422664439EFFBZW8P0733L0M2 & - \\
\hline 3735 & $x$ & & $\begin{array}{l}\text { 1N459766550EFFCG00P0703L0M1 } \\
\text { 1N459766550EFFCG00P0703R0M1 }\end{array}$ & - \\
\hline 3737 & $\mathrm{x}$ & & $\begin{array}{l}\text { 1N459949522EFFCGD3P0703L0M1 } \\
\text { 1N459949522EFFCGD3P0703R0M1 }\end{array}$ & - \\
\hline
\end{tabular}

